\title{
Mechanical Alloying of Elemental Powders into Nanocrystalline (NC) Fe-Cr Alloys: Remarkable Oxidation Resistance of NC Alloys
}

\author{
R. K. Singh Raman ${ }^{1,2}$ (D)
}

1 Department of Mechanical and Aerospace Engineering, Monash University, Clayton, VIC 3800, Australia; raman.singh@monash.edu

2 Department of Chemical Engineering, Monash University, Clayton, VIC 3800, Australia

\begin{abstract}
Mechanical alloying is among the few cost effective techniques for synthesizing nanocrystalline alloy powders. This article reviews mechanical alloying or ball-milling of (NC) powders of $\mathrm{Fe}-\mathrm{Cr}$ alloys of different compositions, and the remarkable oxidation resistance of the NC alloy. The article also reviews challenges in thermal processing of the mechanically alloyed powders (such as compaction into monolithic mass) and means to overcome the challenges.
\end{abstract}

Keywords: nanocrystalline (NC) alloy; microcrystalline (MC) alloy; mechanical alloying; ball-milling; oxidation resistance

\section{Introduction}

Nanocrystalline (NC) structure of alloys (instead of their traditional microcrystalline (MC) counterparts) is reported to remarkably improve some of the properties, such as strength and corrosion resistance [1-4]. Mechanical alloying of powders of the constituent elements is among the most commonly employed approaches for producing NC alloys [2,4-6]. This article reviews challenges in consolidation of mechanically alloyed Fe-Cr powders into monolithic solids and their sintering for achieving close-to-theoretical density, and circumvention of the challenges. The article also presents examples of improvements in oxidation/corrosion resistance properties of a few alloy systems due to the NC structure, and their mechanistic explanations.

Javier S. Blázquez Gámez

Received: 12 March 2021

Accepted: 22 April 2021

Published: 23 April 2021

Publisher's Note: MDPI stays neutral with regard to jurisdictional claims in published maps and institutional affiliations.

\section{Mechanical Alloying for Nanocrystallinity}

A few processing techniques have been employed for synthesis of nanocrystalline (NC) alloys, such as electrodeposition [7], mechanical alloying [2,4-6], severe plastic deformation [8], sputtering, electron beam evaporation, pulse laser ablation [9], gas condensation [9,10], and sol-gel [11]. Some of these techniques (viz., sputtering, electron beam evaporation, pulse laser ablation, gas condensation and sol-gel) have limitations of producing only thin films or tiny samples of NC materials. Several critical applications, such as mechanical or corrosion testing, require bulk monolithic samples. For synthesis of bulk NC materials, mechanical alloying [2,4-6] and electrodeposition [7] have been widely employed.

A few metals [7], and Ni-Fe and Ni-Co alloys [5,6,12,13] were among the early NC metallic materials synthesized by pulsed electrodeposition. However, processing of NC metallic materials by pulsed electrodeposition requires promotion of nucleation and suppression of growth of the depositing grains, and, in order to bias nucleation, organic additives are added to the electrolyte used for electrodeposition [7]. A post-synthesis thermal decomposition is employed for removal of these additives. However, often, the organic additives still remain in the electrodeposited NC material and deteriorate its properties (such as causing embrittlement). In contrast, NC metal and alloy powders synthesized by 
mechanical alloying technique are generally free from such artefacts [2,4-6]. For critical applications such as mechanical or corrosion testing, the mechanically alloyed powders need to be compacted into monolithic mass. Depending on the thermal and mechanical characteristics of NC materials, various techniques have been employed for their compaction [14], such as hot compaction [15], high pressure/lower temperature compaction, in-situ consolidation [16], hot isostatic pressing [17], and explosive compaction [18]. Often, the consolidated material is subjected to sintering in order to achieve the theoretical density. The thermal stability of NC material governs the choice of sintering temperature and time. Examples of mechanical alloying of elemental powders into NC alloy powders of a few systems, their consolidation and sintering, and the associated challenges and circumvention are discussed in the succeeding sections. The role of the NC structure in remarkably influencing oxidation resistance is also discussed.

\section{Mechanical Alloying of Fe-Cr Alloy Powders and Their Consolidation}

Powders of Fe and $\mathrm{Cr}$ (purity: 99.9\%, particle size: $<10 \mu \mathrm{m}$ ) were mechanical alloyed into $\mathrm{Fe}-\mathrm{Cr}$ alloy powders with different $\mathrm{Cr}$ contents $(2,5,10$, and $20 \mathrm{wt} \%)$ for the purpose of investigation of the role of nanocrystalline (NC) structure of $\mathrm{Fe}-\mathrm{Cr}$ alloys in their oxidation/corrosion resistance [19]. NC Fe-Cr alloy powders were synthesized under an inert environment of toluene, using an air-cooled planetary ball-mill ( $300 \mathrm{rpm})$, tungsten carbide balls, and a powder-to-ball weight ratio of 1:10. The ball milling was continued for $20 \mathrm{~h}$, and the crystallite grain size was determined intermittently, from the broadening of X-ray diffraction (XRD) peaks and the Scherrer equation [20]. Figure 1 shows the decrease in the grain size with increasing milling duration and confirms the grain size to have stabilized well and truly in the nanocrystalline regime $(\sim 20 \mathrm{~nm})$ for all the powders, after $15-20 \mathrm{~h}$ of mechanical alloying [21]. It should be noted that the indirect determination of nanocrystalline grain size by XRD has been confirmed by direct measurements by transmission electron microscopy [21].

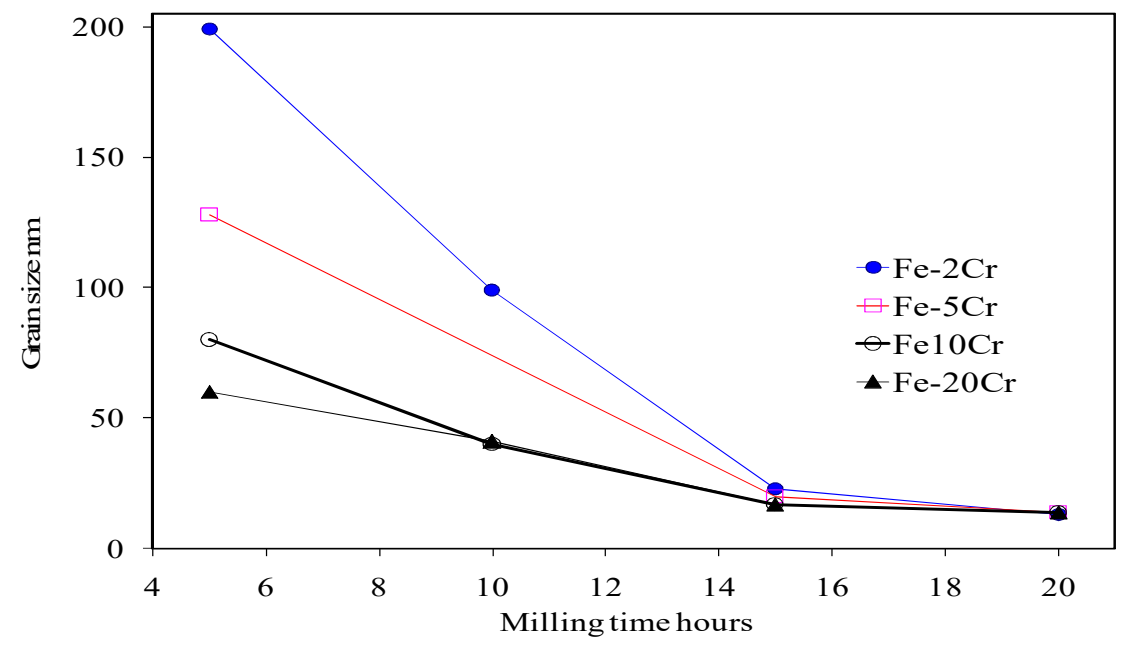

Figure 1. Decrease in the crystallite grain size with increasing duration of milling of elemental powders into Fe-Cr alloy powders with different $\mathrm{Cr}$ contents [21].

As mentioned earlier, for critical applications such as generating specimens for mechanical or corrosion testing, the mechanically alloyed powders need to be compacted into monolithic mass. However, it may be a non-trivial task to accomplish compaction of powders of $\mathrm{NC} \mathrm{Fe}-\mathrm{Cr}$ alloys, because the crystal structure of $\mathrm{Fe}$ and $\mathrm{Fe}-\mathrm{Cr}$ alloys is body centred cubic (BCC), which resist plastic deformation and have high hardness. Therefore, the plastic deformation and material flow that are necessary for an effective compaction required for consolidation of $\mathrm{Fe}$ and $\mathrm{Fe}-\mathrm{Cr}$ alloys necessitate application of high pressures and high temperatures. Seigel [22] reported that for plastic deformation of NC $(10 \mathrm{~nm}) \mathrm{Fe}$ (that has a hardness of $10 \mathrm{GPa}$ ), the pressure needs to be greater than the yield strength, 
i.e., 3.5 GPa ( 1/3rd of hardness), that can be prohibitively high. Therefore, to accomplish compaction at moderate loads, it becomes necessary to elevate the compaction temperature in order to enhance plastic flow. However, the compaction temperature cannot be too high because that will cause excessive grain growth and loss of nanocrystallinity. Therefore, it becomes essential to identify the temperature-time window for accomplishing compaction without allowing excessive grain growth and loss of NC structure.

Malow et al. [23] successfully compacted NC Fe to $~ 100 \%$ of the theoretical density, by employing a pressure of $2.7 \mathrm{GPa}$ at $475^{\circ} \mathrm{C}$. However, when the NC Fe- $10 \mathrm{Cr}$ alloy powder that was prepared as described earlier was compacted at $2 \mathrm{GPa}$ and $515^{\circ} \mathrm{C}$, only $92 \%$ of the theoretical density could be achieved, indicating the need for increasing the compaction temperature. To identify an appropriate temperature-time window for softening of hardened NC Fe-Cr alloy powders but avoiding the excessive grain growth, the mechanically alloyed powders produced as shown in Figure 1 [21] were subjected to annealing at 500, 600 , and $700{ }^{\circ} \mathrm{C}$ in a reducing environment for different durations (3-120 min). The average grain size was determined after intermittent durations of annealing (again, from the broadening of XRD peaks and the Scherrer equation [20]). Figure 2 shows a typical set of XRD spectra for Fe-10Cr alloy mechanically alloyed for 3-120 min at $500{ }^{\circ} \mathrm{C}$. The peaks are seen to broaden with increasing time of annealing because of the increasing grain growth.

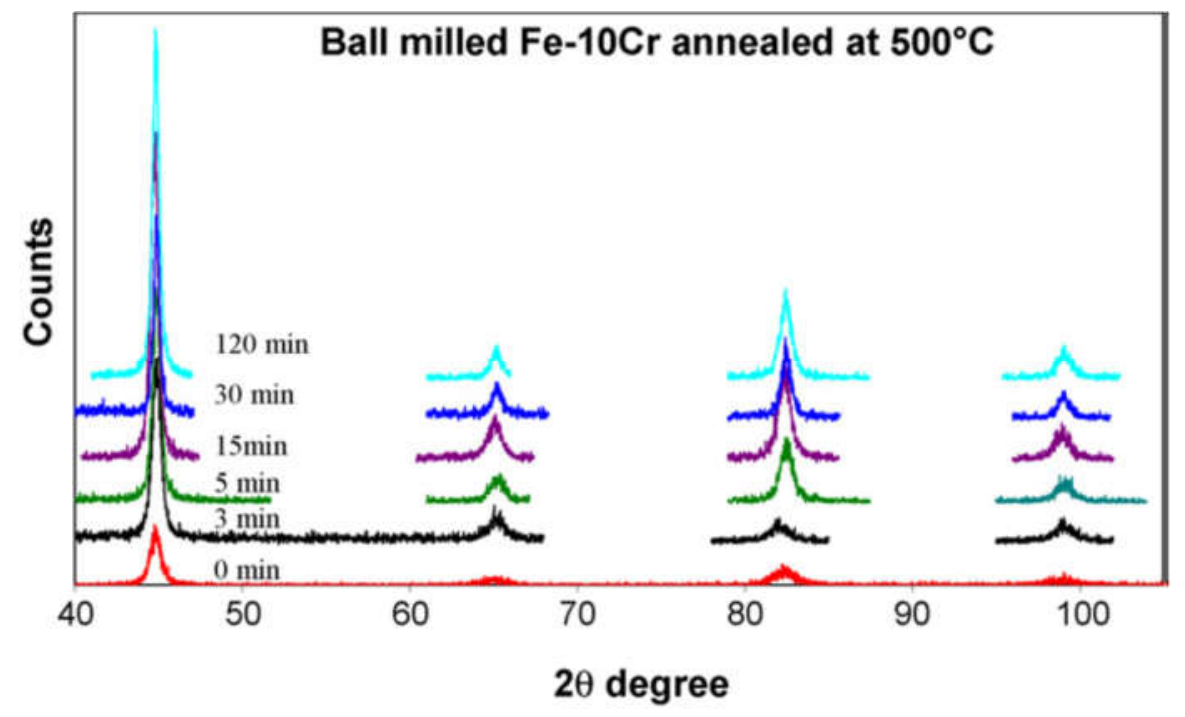

Figure 2. XRD spectra for mechanically alloyed $\mathrm{Fe}-10 \mathrm{Cr}$ alloy annealed for different durations (0-120 $\mathrm{min})$ at $500{ }^{\circ} \mathrm{C}([24]$, reproduced with copyright clearance).

Figure 3 shows the grain growth of Fe-10Cr alloy powder during annealing at 500, 600 , and $700{ }^{\circ} \mathrm{C}$ for durations up to $120 \mathrm{~min}$. Though the grains grow rapidly during the initial stage of annealing at each temperature, the intensity of growth is faster at higher temperatures. Grain growth plateaued after $15 \mathrm{~min}$ at $500{ }^{\circ} \mathrm{C}$, whereas grains continued to grow rapidly at 600 and $700{ }^{\circ} \mathrm{C}$. In fact, at $700{ }^{\circ} \mathrm{C}$, the grain growth was so rapid that after $60 \mathrm{~min}$ the grains tended to grow beyond the nanocrystalline regime. The grain growth took off after $90 \mathrm{~min}$ also at $600^{\circ} \mathrm{C}$. Figure 4 compares the grain growth data for the mechanically alloyed Fe-10Cr NC alloy powder extracted from Figure 3, which are compared with those reported in the literature for ball-milled powders of $\mathrm{NC}$ Fe and an Fe-Al alloy $[9,23-28]$. There are considerable variabilities, particularly at temperatures above $400{ }^{\circ} \mathrm{C}$. Such variabilities are attributed largely to the impurities in the powders. Some impurities such as oxide particles pin the grain boundaries and impede grain growth, and therefore powders with such impurities resist grain growth over higher temperature regimes. So, the purer the NC powder, the greater is its susceptibility to grain growth, and the lower is the temperature at which the rapid grain growth starts. The grain growth impeding due to impurities is more readily offered by alloying elements with greater 
thermodynamic susceptibility to form oxides, for example the Fe-Al alloy in Figure 4 shows resistance to grain growth over a higher temperature regime [28]. In fact, this effect has been successfully exploited for increasing the temperature regime for stability of NC alloys, as will be discussed subsequently.

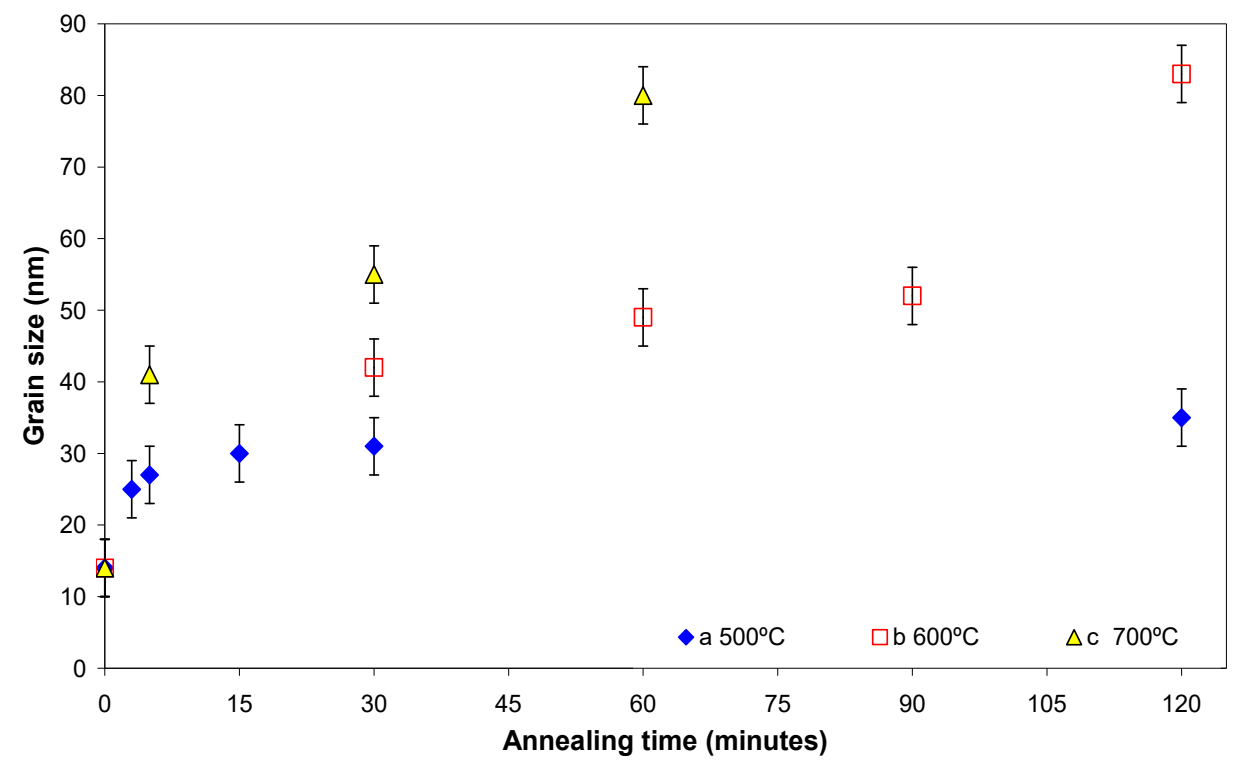

Figure 3. Grain growth of mechanically alloyed Fe-10Cr nanocrystalline alloy powder during annealing at $500{ }^{\circ} \mathrm{C}(\mathbf{a}), 600{ }^{\circ} \mathrm{C}(\mathbf{b})$ and $700{ }^{\circ} \mathrm{C}$ (c) for different durations up to $120 \mathrm{~min}$ ([24], reproduced with copyright clearance].

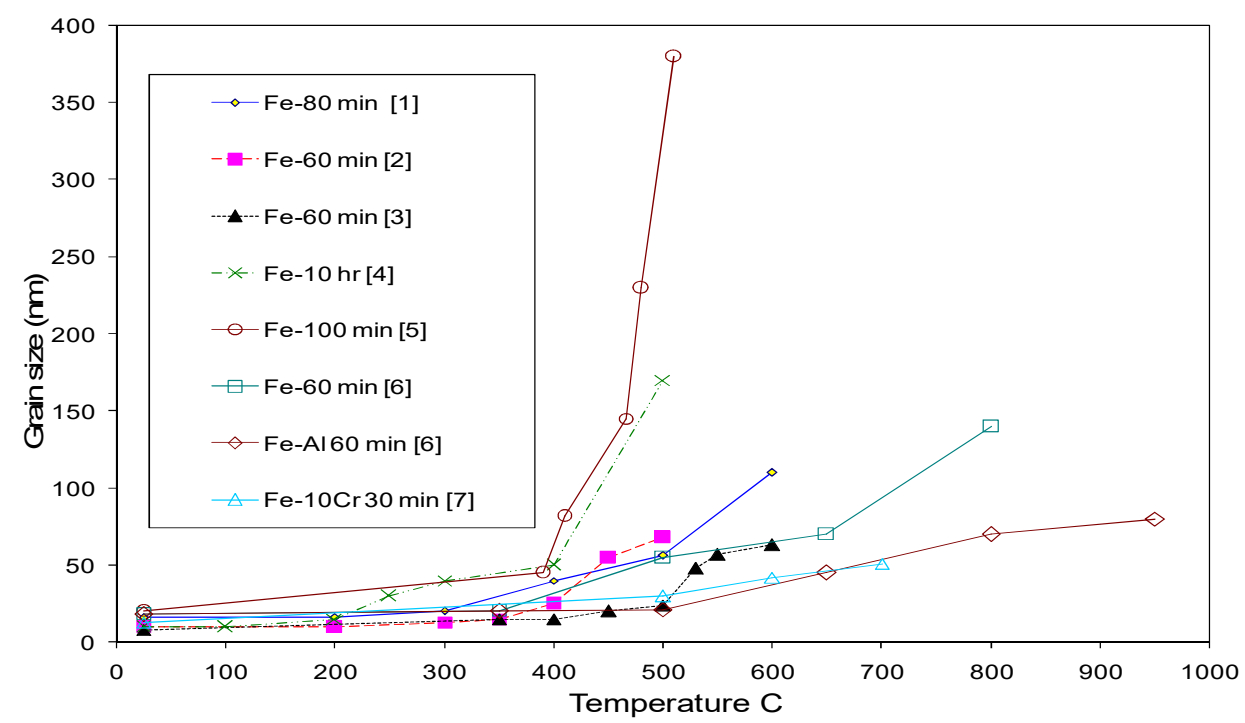

Figure 4. Grain growth data in literature for ball-milled nanocrystalline Fe and two Fe-alloy powders during annealing at different temperatures for different durations: [1] NanoStructured Materials, 6 (1995) 421 (Ref [25]), [2] NanoStructured Materials, 12 (1999) 685 (Ref [26]), [3] Acta Mater, 45 (1997) 2177 (Ref [23]), [4] Progress in Materials Science, 33 (1989) 223 (Ref [9]), [5] Mater. Sci. Forum, 343 (2000) 683 (Ref [27]), [6] NanoStructured Materials 9 (1997) 71 (Ref [28]), and [7] Mater Sci Engineering-A, 494 (2008) $253(\operatorname{Ref}[24])$.

On the basis of the grain growth data in Figure 3, a time-temperature window of $600{ }^{\circ} \mathrm{C}$ and $30 \mathrm{~min}$ was selected for improving ductility and flow of mechanically alloyed $\mathrm{NC}$ powder of $\mathrm{Fe}-10 \mathrm{Cr}$ alloy for successful compaction of the powder into monolithic discs (under a uniaxial pressure of 2.7 GPa). The consolidated discs are seen in Figure 5. The 
density of the discs was determined to be $98 \%$ of the theoretical density. The compacted discs were sintered at $600{ }^{\circ} \mathrm{C}$ for $1 \mathrm{~h}$ to improve the density to $\sim 99 \%$. Again, grain growth data in Figure 3 were the basis for the choice of sintering time and temperature. Grain size of the sintered discs (52 nm) was very much in the nanocrystalline regime.

\section{Oxidation Resistance of Mechanically Alloyed NC Fe-Cr Alloys}

Fe-alloys with sufficient contents of specific alloying elements (namely $\mathrm{Cr}, \mathrm{Al}$ and $\mathrm{Si}$ ) develop a continuous surface layer of oxides of such alloying elements (i.e., $\mathrm{Cr}_{2} \mathrm{O}_{3}, \mathrm{Al}_{2} \mathrm{O}_{3}$ or $\mathrm{SiO}_{2}$ ) that remarkably retards oxidation rate of such alloys. Defect contents of these oxides are remarkably low [29]. As a result, the counter diffusivity of elements involved in oxidation is insignificantly low through the surface layer of such oxides, hence the remarkable oxidation resistance of such alloys. Enabling the development of a continuous surface layer of these protective oxides is the basis for corrosion resistance of alloys. Most common examples are stainless steels (i.e., Fe-Cr alloys) and Al-alloys that readily develop robust surface barrier layers of $\mathrm{Cr}_{2} \mathrm{O}_{3}$ and $\mathrm{Al}_{2} \mathrm{O}_{3}$ respectively, and hence, such alloys possess excellent oxidation/corrosion resistance [29].

The development of a full-fledged continuous external layer of chromia, alumina or silica requires availability of a sufficient amount of the specific alloying elements (viz., $\mathrm{Cr}, \mathrm{Al}$ or Si) at the surface [29]. The critical concentration of such alloying content for a given alloy can be determined by Wagner's calculations [30] (e.g., stainless steels possess $18-20 \mathrm{wt} \% \mathrm{Cr}$ [3]). The critical concentration is governed directly by the diffusivity of the element (and the factors that influence diffusivity, e.g., temperature). It is well-known that at moderately elevated temperatures, grain boundary diffusivity far exceeds the lattice/bulk diffusivity [31]. The temperature range for the $\mathrm{Fe}-\mathrm{Cr}$ system is $300-400{ }^{\circ} \mathrm{C}$ (as shown in Table 1). Therefore, it is obvious that diffusivity will be higher in the case of a nanocrystalline (NC) alloy (that possess remarkably high grain boundary volume fraction [9]) than its microcrystalline counterpart. Indeed, Wang et al. [31] reported the $\mathrm{Cr}$ diffusion in a NC iron to be four orders of magnitude greater than that in its $\mathrm{MC}$ counterpart. On this basis, it was hypothesized that an $\mathrm{Fe}-\mathrm{Cr}$ alloy with sufficient $\mathrm{Cr}$ content will possess much superior oxidation resistance when the structure of the alloy is nanocrystalline $(\mathrm{NC})$ vis-à-vis the same alloy with microcrystalline (MC) structure. On the same basis, it was further hypothesized that with NC structure, considerably lower chromium contents may be sufficient to achieve oxidation resistance similar to common high chromium microcrystalline alloys. These hypotheses were nicely validated by Singh Raman et al. [19,32]. For example, as seen in Figure 5, a NC Fe-10Cr alloy (that was synthesized by mechanical alloying, as described in the preceding section) showed nearly an order of magnitude superior resistance to oxidation than the MC alloy of same composition, during air-oxidation at $300{ }^{\circ} \mathrm{C}$ for $3120 \mathrm{~min}[19,32]$. The secondary ion mass spectroscopy (SIMS) depth profiles of $\mathrm{Cr}$ through the oxide scale thickness (Figure 6) demonstrate the remarkably higher $\mathrm{Cr}$ contents of the protective oxide layer of the $\mathrm{NC}$ alloy than that in the MC alloy, thus accounting for the remarkably superior oxidation resistance of the NC alloy [19]. In fact, it took some time (120 min) for sufficient $\mathrm{Cr}$ to enrich in the oxide layer to develop a full-fledged protective layer of $\mathrm{Cr}_{2} \mathrm{O}_{3}$. At this stage, the oxidation rate of NC alloy became insignificant and similar to that for a stainless steel (that possess $\sim 20 \mathrm{wt} \% \mathrm{Cr}$ ), whereas the MC alloy continued to oxidize at a high rate because of its inability to form a full-fledged protective layer of $\mathrm{Cr}_{2} \mathrm{O}_{3}$. It was possible to explain the stark difference in colour of the NC and MC alloy oxidized for $3120 \mathrm{~min}$ (interested readers may refer to [32] for the explanation). 
Table 1. Diffusion coefficients of $\mathrm{Cr}$ in NC and MC iron [31].

\begin{tabular}{ccccc}
\hline Temperature & Lattice $\left(\mathbf{D}_{\mathbf{b}}\right) \mathbf{~ m}^{2} / \mathbf{s}$ & GB $\left(\mathbf{D}_{\mathbf{b}}\right) \mathbf{~ m}^{2} / \mathbf{s}$ & NC Iron $\left(\mathbf{D}_{\mathbf{n}}\right) \mathbf{~ m}^{2} / \mathbf{s}$ & MC Iron $\left(\mathbf{D}_{\mathbf{m}}\right) \mathbf{~ m}^{2} / \mathbf{s}$ \\
\hline $300^{\circ} \mathrm{C}$ & $1.2 \times 10^{-26}$ & $8.6 \times 10^{-22}$ & $1.7 \times 10^{-17}$ & - \\
$340^{\circ} \mathrm{C}$ & $3.7 \times 10^{-25}$ & $1.7 \times 10^{-20}$ & $1.6 \times 10^{-16}$ & - \\
$380^{\circ} \mathrm{C}$ & $7.6 \times 10^{-24}$ & $2.3 \times 10^{-19}$ & $2.8 \times 10^{-15}$ & $3.6 \times 10^{-19}$ \\
$840^{\circ} \mathrm{C}$ & $1.5 \times 10^{-15}$ & $3.7 \times 10^{-12}$ & - & $2.2 \times 10^{-15}$ \\
\hline
\end{tabular}

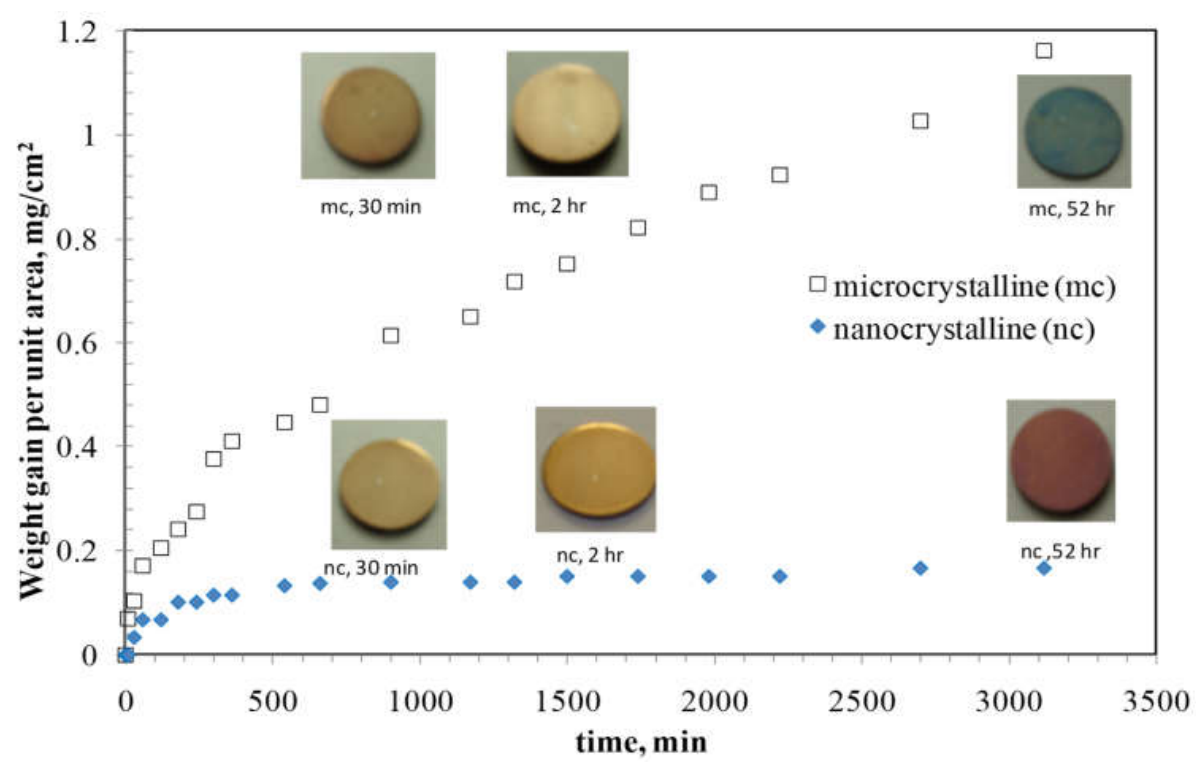

Figure 5. Oxidation kinetics (weight gain versus time plots) of $\mathrm{Fe}-10 \mathrm{Cr}$ alloy with nanocrystalline (nc) and microcrystalline (mc) structures oxidized at $300{ }^{\circ} \mathrm{C}$ for $3120 \mathrm{~min}$ (insets, show colour of the oxidized samples at different stages of oxidation) ([32], reproduced with copyright clearance).

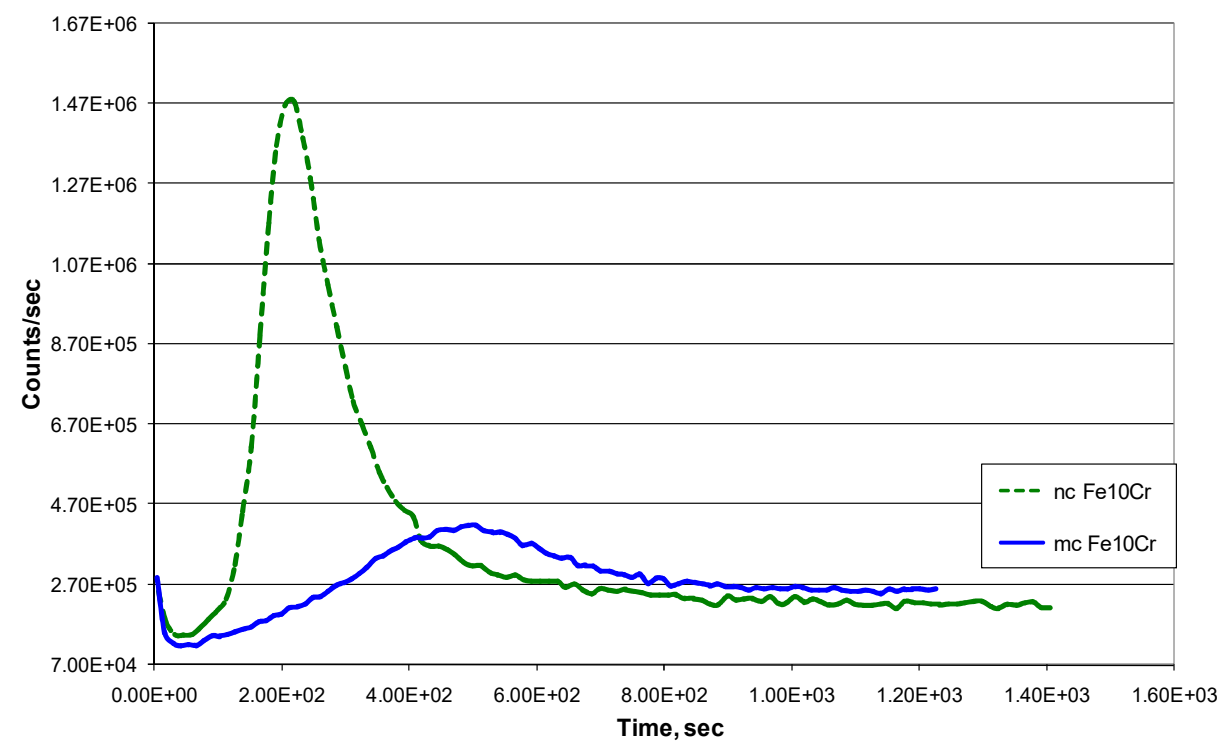

Figure 6. SIMS depth profiles for $\mathrm{Cr}$ in the oxide scale of $\mathrm{Fe}-10 \% \mathrm{Cr}$ alloy with nanocrystalline (nc or NC) and microcrystalline (mc or MC) structures, oxidized for $120 \mathrm{~h}$ in air at $300^{\circ} \mathrm{C}$ alloys. ([19], reproduced with copyright clearance).

\section{Mechanical Alloying of Fe-Cr-Ni-Zr Alloy Powders and Their Consolidation}

As shown in Figure 3, mechanically alloyed Fe-Cr nanocrystalline (NC) powders undergo rapid grain growth when annealed at temperatures above $600-700{ }^{\circ} \mathrm{C}$. Therefore, such powders can lose nanocrystallinity upon exposures to higher temperatures, which 
means temperatures must be $<700{ }^{\circ} \mathrm{C}$ for: (a) further thermal processing of such $\mathrm{NC}$ powders (such as consolidation/sintering, as described in the preceding section) and (b) applications where the NC structure of alloy is required (such as high temperature oxidation resistant NC alloys). Therefore, it is highly attractive to explore means for retaining nanocrystallinity of mechanically alloyed $\mathrm{Fe}-\mathrm{Cr}$ alloyed powders at temperatures $>700{ }^{\circ} \mathrm{C}$. As described in the preceding section, impurities such as oxide particles pin the grain boundaries and impede grain growth, and as a result, some NC powders of Fe and $\mathrm{Fe}-\mathrm{Cr}$ alloy resisted grain growth until higher temperature, as shown in Figure 4. Zr readily forms oxides that are thermodynamically stable up to very high temperatures. Following the ball-milling procedure described earlier, $\mathrm{Fe}, \mathrm{Cr}$, and $\mathrm{Ni}$ powders with and without 2 $w t \% \mathrm{Zr}$ were mechanically alloyed to synthesize NC Fe-10Cr-5Ni and Fe-10Cr-5Ni-2Zr alloy powders, with an objective of increasing the high temperature processibility of the powders, such as compaction at higher temperature, due to $\mathrm{Zr}$ addition [33]. The alloy was added with $5 \mathrm{wt} \% \mathrm{Ni}$, for improving ductility of the compacted alloy, since NC alloys are known to suffer from poor ductility $[1,2,33]$. It should be noted that in the relatively recent times, researchers have successfully employed spark plasma sintering for in-situ consolidation [34].

Grain size of the Fe-10Cr-5Ni alloy powders with and without $\mathrm{Zr}$ addition was measured by XRD technique (as described earlier) after annealing for $1 \mathrm{~h}$ at various temperatures. As shown in Figure 7, NC powder of Zr-containing alloy resists grain growth during annealing at much higher temperatures. In fact, grain size of $\mathrm{Zr}$-containing $\mathrm{NC}$ alloy powder remains well within $\mathrm{NC}$ regime upon annealing even at $1000^{\circ} \mathrm{C}$, whereas the $\mathrm{Zr}$-free alloy undergoes rapid grain growth during $1 \mathrm{~h}$ annealing at $700{ }^{\circ} \mathrm{C}$ and the grains grow into the regime of $>100 \mathrm{~nm}$. Mechanically alloyed NC powder of $\mathrm{Fe}-10 \mathrm{Cr}-$ $5 \mathrm{Ni}-2 \mathrm{Zr}$ was hot-compacted at $400{ }^{\circ} \mathrm{C}$ into discs that could be sintered at a very high temperature $\left(1000{ }^{\circ} \mathrm{C}\right)$, on the basis of the grain growth data shown in Figure 7 [33]. For improving ductility, the $\mathrm{NC}$ Fe-10Cr-5Ni-2Zr alloy powder was mixed with an equal amount of microcrystalline (MC) Fe-10Cr-5Ni-2Zr alloy powder and compacted/sintered into discs of Fe-10Cr-5Ni-2Zr alloy with bimodal grain size distribution (50\% NC + 50\% $\mathrm{MC}$ ). The alloy with bimodal grain size distribution showed improved ductility [33]. In simple terms, the bimodal alloy has considerable $(50 \%)$ MC component where dislocations can travel greater distance before being pinned, and hence better ductility.

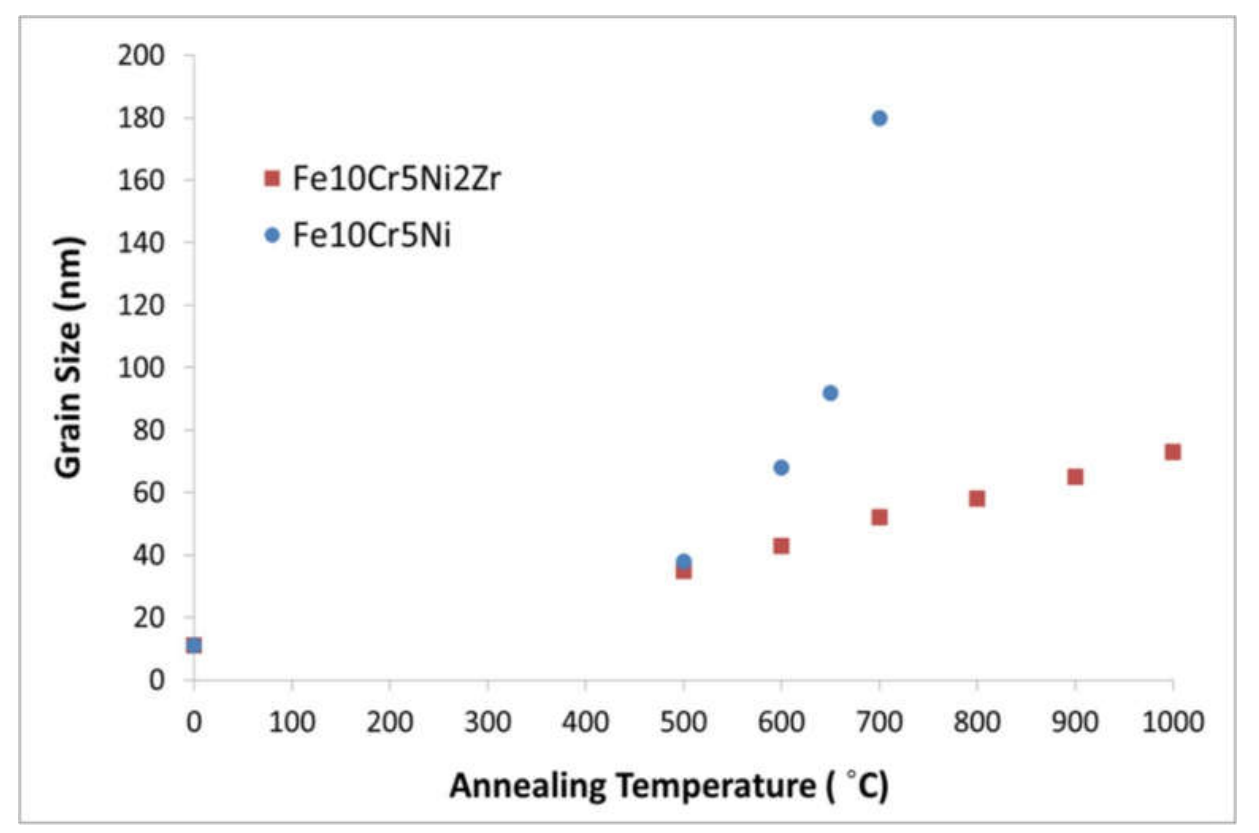

Figure 7. Grain growth of Fe-10Cr-5Ni alloys with and without $\mathrm{Zr}$, after annealing for $1 \mathrm{~h}$ at different temperatures [33], reproduced with copyright clearance. 


\section{Oxidation Resistance of Mechanically Alloyed NC Fe-Cr-Ni-Zr Alloys}

Oxidation resistance of $\mathrm{NC} \mathrm{Fe-Cr}$ alloys has been shown to be considerably superior to that of their MC counterparts [3], as also seen in Figure 5, and the reasons for the superior oxidation resistance of NC alloy is discussed in the literature [32] and summarized in the preceding section. Consistent with this trend, nanocrystalline $\mathrm{Fe}-10 \mathrm{Cr}-5 \mathrm{Ni}-2 \mathrm{Zr}$ alloy oxidized at much slower rate than its microcrystalline counterpart, as shown in Figure 8 . The role of nanocrystalline structure in improving oxidation resistance is further supported from the observation that the $\mathrm{Fe}-10 \mathrm{Cr}-5 \mathrm{Ni}-2 \mathrm{Zr}$ alloy with bimodal grain size distribution (i.e., 50\% nanocrystalline and 50\% microcrystalline content) oxidized at somewhat higher rate (Figure 8), because of their smaller nanocrystalline content. The most striking observation was that the oxidation resistance of nanocrystalline $\mathrm{Fe}-10 \mathrm{Cr}-5 \mathrm{Ni}-2 \mathrm{Zr}$ alloy $\mathrm{Cr}$ ) was in the same regime as that of a microcrystalline $\mathrm{Fe}-20 \mathrm{Cr}-5 \mathrm{Ni}$ alloy (whose $20 \% \mathrm{Cr}$ content is similar to a common stainless steel.) The SIMS depth profiles of $\mathrm{Cr}$ through the oxide scale thickness (Figure 9) show considerably lower $\mathrm{Cr}$ contents of the protective oxide layer of the microcrystalline $\mathrm{Fe}-10 \mathrm{Cr}-5 \mathrm{Ni}-2 \mathrm{Zr}$ alloy, whereas the $\mathrm{Cr}$ content was considerably higher in protective oxide of all the alloys with high oxidation resistance [33]. In fact, the relative $\mathrm{Cr}$ contents of the protective oxide scales of various alloys commensurate well with their corresponding oxidation resistance.

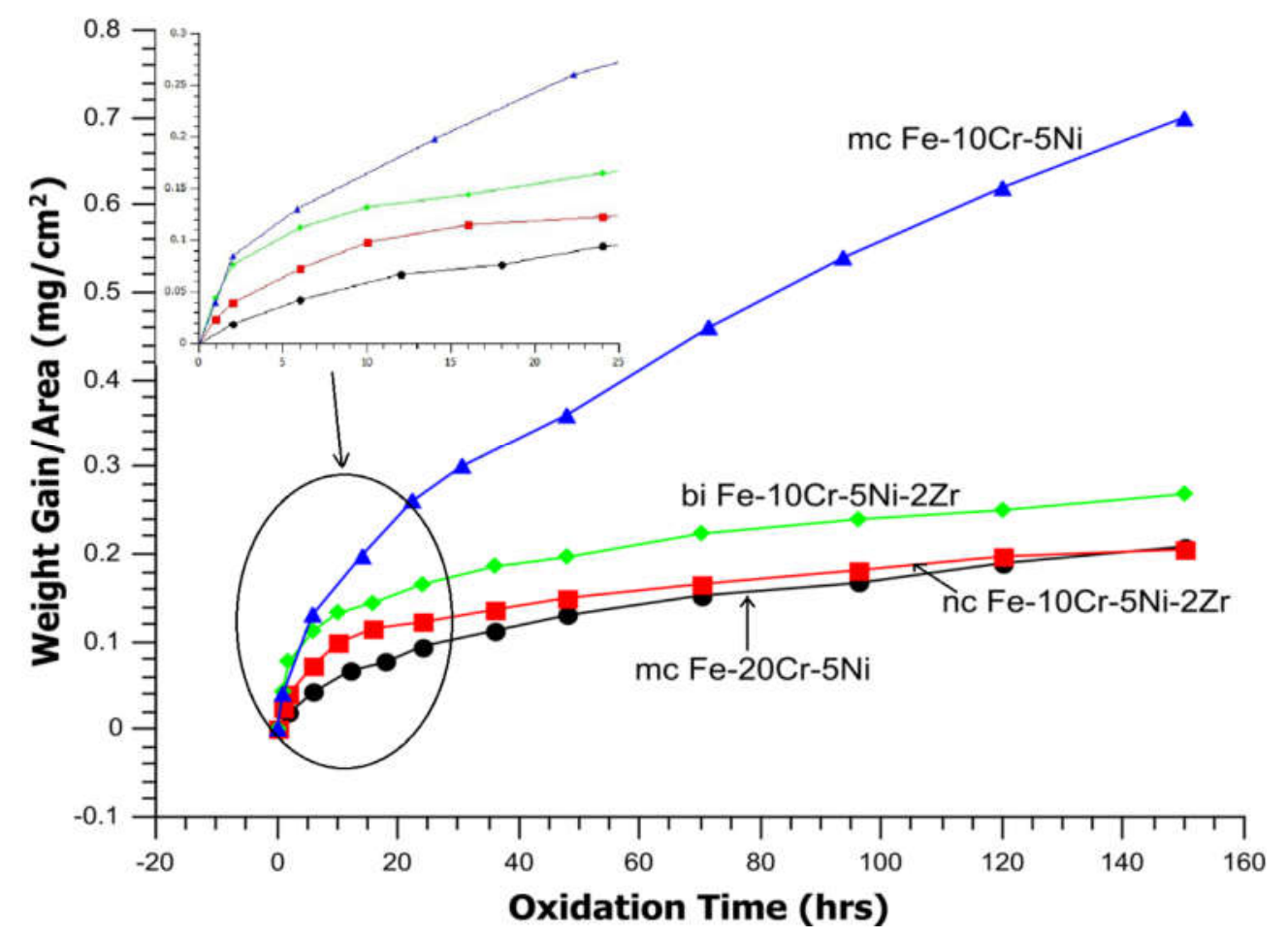

Figure 8. Oxidation kinetics of the nanocrystalline (nc), bimodal (bi), and microcrystalline (mc) alloys at $550{ }^{\circ} \mathrm{C}$. The inset shows the difference in the oxidation kinetics trend during the initial stages of oxidation. ([33], reproduced with copyright clearance). 


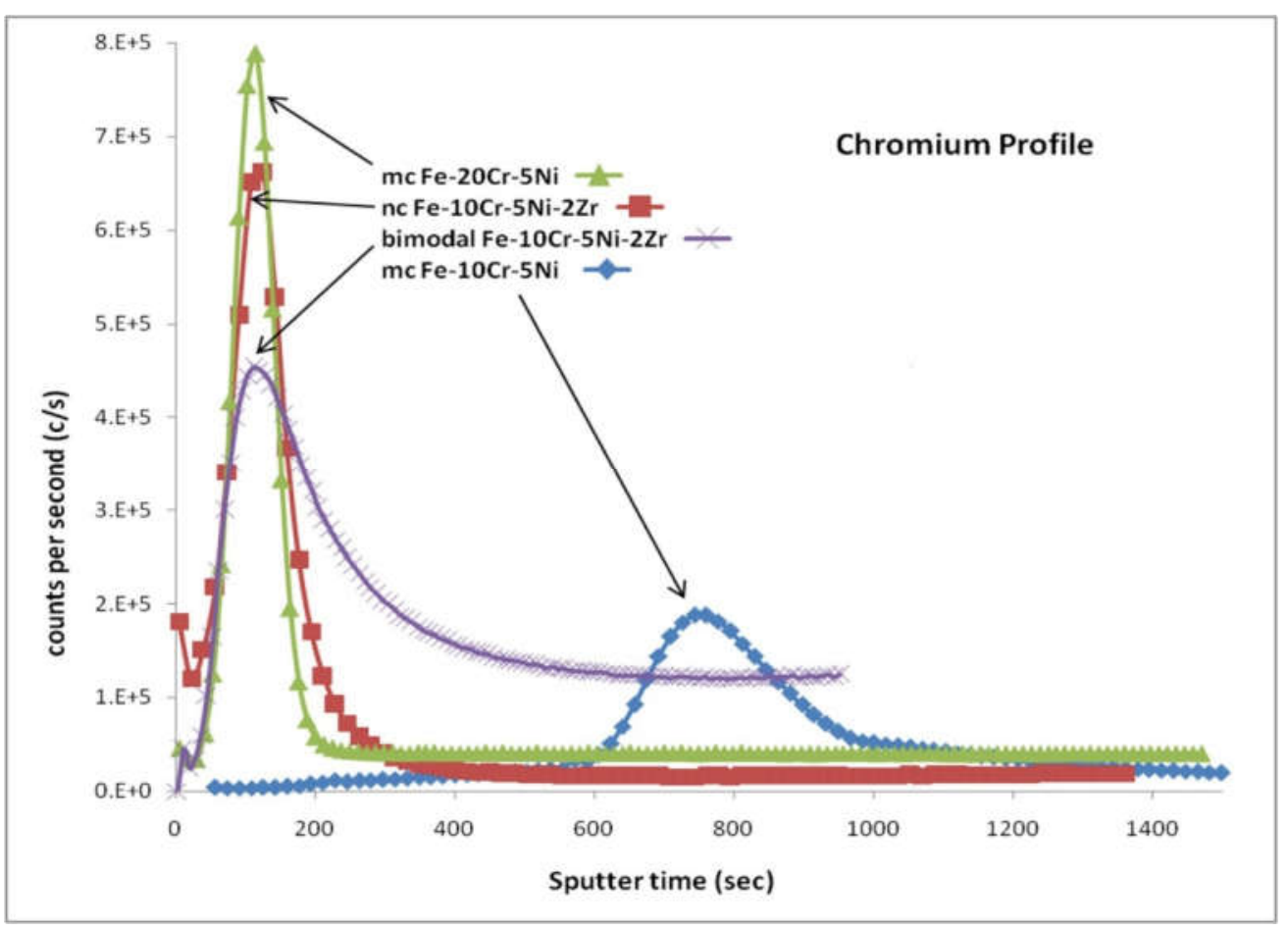

Figure 9. Cr depth profile for oxidised alloys described in Figure 8 (above) measured using secondary ion mass spectroscopy (SIMS). ([33], reproduced with copyright clearance).

\section{Opportunities}

It is well known [29] that the defect content of $\mathrm{Al}_{2} \mathrm{O}_{3}$ is considerably less than that of $\mathrm{Cr}_{2} \mathrm{O}_{3}$, and hence a surface layer of $\mathrm{Al}_{2} \mathrm{O}_{3}$ is more protective. However, at the $\mathrm{Al}$ contents required for developing a continuous protective layer of $\mathrm{Al}_{2} \mathrm{O}_{3}$ on a steel, the alloy will suffer from unacceptable loss in mechanical property (such as loss of toughness). However, it has been possible to develop $\mathrm{Al}_{2} \mathrm{O}_{3}$ layer on $\mathrm{Fe}-\mathrm{Cr}-\mathrm{Al}$ and $\mathrm{Ni}-\mathrm{Cr}-\mathrm{Al}$ alloys (that have acceptably low $\mathrm{Al}$ contents), with the help of the phenomenon called, "third element effect" [29]. In this phenomenon, the alloy with sufficient $\mathrm{Cr}$ first forms a continuous layer of $\mathrm{Cr}_{2} \mathrm{O}_{3}$, which stops outward diffusion of $\mathrm{Al}$, thereby facilitating $\mathrm{Al}$ accumulation (just underneath the $\mathrm{Cr}_{2} \mathrm{O}_{3}$ layer) to the level that is sufficient for the development of a full-fledged layer of $\mathrm{Al}_{2} \mathrm{O}_{3}$. Thus, with the "third element effect" of $\mathrm{Cr}$, the alloy develops a protective layer of $\mathrm{Al}_{2} \mathrm{O}_{3}$ in spite of the low $\mathrm{Al}$ content of the alloy. As discussed in the preceding sections, $\mathrm{NC}$ structure profoundly accelerates diffusion; hence, it is expected to facilitate the "third element effect". Therefore, it will be interesting to investigate the role of NC structure of mechanically alloyed systems in promoting the "third element effect".

\section{Conclusions}

Nanocrystalline (NC) powders of Fe-Cr alloys can be synthesized by mechanical alloying. However, consolidation of these powders into monolithic mass is a challenge because of their high hardness due to body-centered cubic crystalline structure of $\mathrm{Fe}-\mathrm{Cr}$ systems. In order to promote plastic flow, compaction is required to be carried out at high temperatures; however, too high a temperature can cause grain growth and loss of NC structure. A temperature-time window is optimized for hot-compaction of NC powders of $\mathrm{Fe}-\mathrm{Cr}$ alloys without losing NC structure. In order to enable hot processing of the powders at much higher temperatures without losing NC structure, $\mathrm{Zr}$ was added to the alloy during mechanical alloying that pins grain boundaries and suppresses grain growth. As a result, compaction temperature of powders of Fe-10Cr-5Ni-2Zr alloy can be as high as $1000{ }^{\circ} \mathrm{C}$. 
Oxidation resistance of compacted nanocrystalline (NC) Fe-10Cr alloy is found to be remarkably superior to its microcrystalline (MC) counterpart. The superior oxidation resistance of NC alloy is attributed to the much greater grain boundary volume of NC structure that causes sufficient diffusion of $\mathrm{Cr}$ in oxide layer and development of a protective layer of Cr-oxide, whereas the MC alloy fails to develop this protective layer because of insufficient $\mathrm{Cr}$ diffusion. In fact, $\mathrm{Cr}$ content of the protective oxide layer developed during oxidation of $\mathrm{NC} \mathrm{Fe}-10 \mathrm{Cr}-5 \mathrm{Ni}-2 \mathrm{Zr}$ alloy at $550{ }^{\circ} \mathrm{C}$ is similar to that of a MC Fe-20Cr alloy (i.e., common stainless steel); hence, the two alloys show similar oxidation resistance. Regarding further opportunities, it will be interesting to investigate the role of NC structure of mechanically alloyed systems in promoting the "third element effect".

Funding: This research received no external funding.

Institutional Review Board Statement: Not applicable.

Informed Consent Statement: Not applicable.

Data Availability Statement: Data is contained within the article.

Conflicts of Interest: The author declares no conflict of interest.

\section{References}

1. Kumar, K.; Van Swygenhoven, H.; Suresh, S. Mechanical behavior of nanocrystalline metals and alloys. Acta Mater. 2003, 51, 5743-5774. [CrossRef]

2. Suryanarayana, C.; Froes, F. The structure and mechanical properties of metallic nanocrystals. Metall. Trans. A 1992, 23, 1071-1081. [CrossRef]

3. Mahesh, B.V.; Raman, R.K.S. Role of Nanostructure in Electrochemical Corrosion and High Temperature Oxidation: A Review. Metall. Mater. Trans. A 2014, 45, 5799-5822. [CrossRef]

4. Koch, C.C.; Youssef, K.M.; Scattergood, R.O.; Murty, K.L. Breakthroughs in Optimization of Mechanical Properties of Nanostructured Metals and Alloys. Adv. Eng. Mater. 2005, 7, 787-794. [CrossRef]

5. Rofagha, R.; Langer, R.; El-Sherik, A.M.; Erb, U.; Palumbo, G.; Aust, K.T. The corrosion behaviour of nanocrystalline nickel. Scripta Metall. Mater. 1991, 25, 2867. [CrossRef]

6. Rofagha, R.; Erb, U.; Ostrander, D.; Palumbo, G.; Aust, K.T. The effects of grain size and phosphorus on the corrosion of nanocrystalline Ni-P alloys. Nanostruct. Mater. 1993, 2, 1-10.

7. Karimpoor, A.A.; Erb, U.; Aust, K.T.; Palumbo, G. High strength nanocrystalline cobalt with high tensile ductility. Scripta Mater. 2003, 49, 651-656. [CrossRef]

8. Cheng, S.; Ma, E.; Wang, Y.M.; Kecskes, L.J.; Youssef, K.M.; Koch, C.C.; Trociewitz, U.P.; Han, K. Tensile properties of in situ consolidated nanocrystalline Cu. Acta Mater. 2005, 53, 1521. [CrossRef]

9. Gleiter, H. Nanocrystalline materials. Prog. Mater. Sci. 1989, 33, 223.

10. Trapp, S.; Limbach, C.T.; Gonser, U.; Campbell, S.J.; Gleiter, H. Enhanced Compressibility and Pressure-Induced Structural Changes of Nanocrystalline Iron: In Situ Mössbauer Spectroscopy. Phys. Rev. Lett. 1995, 75, 3760. [CrossRef] [PubMed]

11. Roy, R.A.; Roy, R. Diphasic xerogels: I. Ceramic-metal composites. Mater. Res. Bull. 1984, 19, 169-177. [CrossRef]

12. Seo, J.H.; Kim, J.K.; Yim, T.H.; Park, Y.B. Textures and Grain Growth in Nanocrystalline Fe-Ni Alloys. Mater. Sci. Forum 2005, 475-479, 3483-3488. [CrossRef]

13. Hibbard, G.D.; Aust, K.T.; Erb, U. Thermal stability of electrodeposited nanocrystalline Ni-Co alloys. Mater. Sci. Eng. A 2006, 433, 195-202. [CrossRef]

14. Groza, J.R. Nanocrystalline Powder Consolidation Methods. In Nanostructured Materials: Processing, Properties, and Applications; Koch, C.C., Ed.; William Andrew Pub.: Norwich, NY, USA, 2007.

15. Rawers, F.; Biancaniello, R.; Jiggets, R.; Fields, R.; Williams, M. Warm-hip compaction of attrition-milled iron alloy powders. Scr. Mater. 1999, 40, 277. [CrossRef]

16. Youssef, K.M.; Scattergood, R.O.; Murty, K.L.; Koch, C.C. Ultratough nanocrystalline copper with a narrow grain size distribution. Appl. Phys. Lett. 2004, 85, 929. [CrossRef]

17. Elkedim, O.; Cao, H.S.; Guay, D. Preparation and corrosion behavior of nanocrystalline iron gradient materials produced by powder processing. J. Mater. Process. Technol. 2002, 121, 383. [CrossRef]

18. Guruswamy, S.; Loveless, M.R.; Srisukhumbowornchai, N.; McCarter, M.K.; Teter, J.P. Processing of Terfenol-D alloy based magnetostrictive composites by dynamic compaction. IEEE Trans. 2000, 36, 3219-3222. [CrossRef]

19. Raman, R.K.S.; Gupta, R.K. Oxidation Resistance of Nanocrystalline vis-à-vis Microcrystalline Fe-Cr Alloys. Corros. Sci. 2009, 51, 316-321. [CrossRef]

20. Klug, H.P.; Alexander, L. X-ray Diffraction Procedures for Polycrystalline and Amorphous Materials, 2nd ed.; Wiley-VCH: Weinheim, Germany, 1974. 
21. Gupta, R.K. Synthesis and Corrosion Behavior of Nanocrystalline Fe-Cr Alloys. Ph.D. Thesis, Monash University, Melbourne, Australia, 6 May 2010.

22. Siegel, R.W. Mechanical properties of nanophase materials. Mater. Sci. Forum 1997, 235-238, 851.

23. Malow, T.A.; Koch, C.C. Grain growth in nanocrystalline iron prepared by mechanical attrition. Acta Mater. $1997,45,2177$. [CrossRef]

24. Gupta, R.K.; Raman, R.K.S.; Koch, C.C. Grain Growth Behaviour and Consolidation of Ball Milled Nanocrystalline Fe-10Cr Alloy. Mater. Sci. Eng. A 2008, 494, 253-256. [CrossRef]

25. Moelle, C.H.; Fecht, H.J. Thermal stability of nanocrystalline iron prepared by mechanical attrition. NanoStructured Mater. 1995, 6, 421. [CrossRef]

26. Bonetti, E.; del Bianco, L.; Pasquini, L.; Sampaolesi, E. Thermal evolution of ball milled nanocrystalline iron. NanoStructured Mater. 1999, 12, 685. [CrossRef]

27. Natter, H.; Schmelzer, M.; Loeffler, M.S.; Hempelmann, R. In-situ X-ray crystallite growth study on nanocrystalline Fe. J. Metastable Nanocryst. Mater. 2000, 8, 683-688. [CrossRef]

28. Perez, R.J.; Jiang, H.G.; Lavernia, E.J. Grain size stability of nanocrystalline cryomilled Fe-3wt.\% Al alloy. NanoStructured Mater. 1997, 9, 71. [CrossRef]

29. Kofstad, P. High Temperature Corrosion; Elsevier Applied Science and Publishers Ltd.: New York, NY, USA, 1988.

30. Wagner, C. Oxidation of alloys involving noble metals. J. Electrochem. Soc. 1952, 99, 103. [CrossRef]

31. Wang, Z.B.; Tao, N.R.; Tong, W.P.; Lu, J.; Lu, K. Diffusion of chromium in nanocrystalline iron produced by means of surface mechanical attrition treatment. Acta Mater. 2003, 51, 4319. [CrossRef]

32. Raman, R.K.S.; Gupta, R.K.; Koch, C.C. Synthesis Challenges and Extraordinary Resistance to Environmental Degradation of Nanocrystalline vis-à-vis Microcrystalline Fe-Cr Alloys. Philos. Mag. 2010, 90, 3233-3260. [CrossRef]

33. Mahesh, B.V.; Raman, R.K.S.; Koch, C.C. Bimodal grain size distribution: An effective approach for improving the mechanical and corrosion properties of Fe-Cr-Ni alloys. J. Mater. Sci. 2012, 47, 7735-7743. [CrossRef]

34. Kumar, R.; Bakshi, S.R.; Joardar, J.; Parida, S.; Raja, V.S.; Raman, R.K.S. Structural Evolution During Milling, Annealing and Rapid Consolidation of Nanocrystalline Fe-10Cr-3Al Powder. Materials 2017, 10, 272. [CrossRef] [PubMed] 